\title{
Innovación en el deshidratado solar
}

\author{
Innovation on solar dehydrator
}

Jaime Espinoza S. ${ }^{1 *}$

Recibido 11 de enero de 2016, aceptado 26 de mayo de 2016

Received: January 11, 2016 Accepted: May 26, 2016

\begin{abstract}
RESUMEN
Como parte de la caracterización del estado del arte del deshidratado solar, se consultó el patentamiento de tecnologías similares en el mundo, centrándose la búsqueda en EE.UU. (USPTO), Unión Europea y resto del mundo, con términos "deshidratador (dehydrator)", "solar (solar)", "secador de alimentos (food dryer)" y "secador solar (solar dryer)". Se presentan aquí las innovaciones orientadas al deshidratado de productos que funcionen en base a la circulación de aire caliente solar que previamente hayan circulado por cámara que hacen las veces de paredes para enviar este aire al interior donde se ubica el producto a deshidratar. El desarrollo tecnológico está orientado a apoyar el deshidratado de la pequeña o mediana producción. Para procesos industriales por sobre las tres toneladas de secado o deshidratado diario, se implementó un "techo solar activo" que modifica la cubierta de galpones industriales incorporándole un doble techo de policarbonato logrando con ello precalentar el aire con energía solar, disminuyendo entre 50 a 100\% el uso de gas utilizado en este proceso. Los recientes desarrollos se enfocaron a diseñar deshidratadores solares para producción menor a $1.000 \mathrm{~kg}$ diarios. Para ello se diseñó un contenedor deshidratador solar factible de ser utilizado con diversos productos agrícolas, compacto, modular, móvil, en tanto para los pequeños emprendedores, con una producción diaria de unos $30 \mathrm{~kg}$, se diseñó un deshidratador solar compacto con apoyo fotovoltaico para funcionamiento sin red. Se dispone de experiencias en terreno y en laboratorio con uva, durazno, nueces, manzana, tomate y naranja. Se ha logrado un evidente impacto en la calidad final del producto. Con este equipamiento se abren nuevas opciones de emprendimiento, reducción de mermas y exportación con sello verde.
\end{abstract}

Palabras clave: Deshidratado solar, innovación en procesamiento de alimentos.

\begin{abstract}
As part of the characterization of the state of the art solar dryer, the patenting of similar technologies in the world was consulted, focusing the search on US \& European Patent Offices and elsewhere, with terms "solar dehydrator", "solar food dryer" and "solar dryer". This work is oriented toward innovations of dehydrated products by means of supplying solar hot air previously circulated through walls to send this air into the product to dehydrate. Technological development was oriented towards solar drying for medium or small production. For industrial processes above 3 tonnes of daily dried product an "active solar roof" was implemented. This modifies the roof of industrial building -incorporating a double plate of polycarbonate, that allows a solar air heating, allowing a reduction between $50 \%$ to $100 \%$ in fuel consumption used in this process. Other innovations are focused on solar dehydrators for daily production less than $1000 \mathrm{~kg}$. A solar dehydrator container was designed to be used with various agricultural products, with special characteristics like integrated, modular and transportable design. For the small entrepreneurs, with a daily production of about $30 \mathrm{~kg}$, a compact solar dehydrator was designed including a photovoltaic unit as energy supply for independent operation. Practical experiences with grapes, peaches, walnuts, apple, tomatoes and orange were carried on. As a result of this an evident impact on the final quality of the product was achieved. With this equipment new options of entrepreneurship, reducing wastage and exportation are now possible.
\end{abstract}

Keywords: Solar dehydrator, innovation on food processing.

\footnotetext{
1 Departamento de Ingeniería Mecánica. Universidad Técnica Federico Santa María. Casilla 110-V. Valparaíso, Chile. E-mail: jaime.espinoza@usm.cl

* Autor de correspondencia
} 


\section{INTRODUCCIÓN}

Deshidratación o secado es un método de procesamiento de alimentos mediante la aplicación de calor, específicamente de aire caliente. Es un procedimiento simultáneo de transferencia de calor y de masa, acompañado de un cambio de fase. Se define como "la aplicación de calor bajo condiciones controladas para remover la mayoría del agua normalmente presente en los alimentos mediante evaporación".

El deshidratado de alimentos es uno de los métodos más antiguos de conservación de alimentos. El principal propósito es extender la duración de estos por la reducción del agua contenida en ellos; de esta forma se inhibe el crecimiento microbiano y la actividad enzimática, pero la temperatura del proceso es generalmente insuficiente para causar su inactivación. Por lo tanto, cualquier aumento en la humedad contenida durante el almacenamiento, como por ejemplo debido a empaque defectuoso puede resultar en un rápido deterioro.

La reducción de peso y volumen resultan en una reducción de costos de transporte y almacenamiento. Generalmente se considera un procedimiento de alto costo, debido a la energía requerida.

En Chile existe una restringida oferta de servicios de deshidratación para pequeños productores. Los disponibles se centralizan en la utilización de gas, cuyos alto costos de inversión y crecientes costos de operación limitan la competitividad. La actual producción artesanal se basa en la deshidratación al sol en forma directa, lo que conlleva mala calidad del producto por la alta radiación solar, falencias sanitarias, que implican la presencia de polvo, piedras y restos orgánicos, entre otros. Los problemas mencionados implican una restricción de acceso a mercados internacionales con intereses en la producción "verde".

El mercado nacional alcanzó el 2013 un total de exportaciones de frutos secos y deshidratados de US\$ 77 millones, con un crecimiento de $102,1 \%$ en los últimos cinco años. Este mercado se encuentra actualmente en medio de un período de fuerte expansión y posicionamiento internacional, con exportaciones que alcanzan los US\$ 700 millones a nivel mundial.
Chile ya es el exportador mundial número uno de ciruelas deshidratadas, con más de 14.000 hectáreas plantadas; y el tercer exportador mundial de nueces, con más de 31.000 hectáreas plantadas. Además ya existen cerca de 14.000 hectáreas plantadas en nuevas especies como las avellanas. En concepto de exportaciones, el deshidratado representa más de US\$ 700 millones, y se estima que a fines del presente año estas alcancen los US\$ 1.000 millones. La categoría completa de fruta seca ha duplicado su producción en los últimos diez años.

El mercado descrito actualmente deshidrata sus productos de forma tradicional, es decir, en base a gas licuado de petróleo y secado al sol en forma directa. No existe información de amplia participación de energías renovables en la forma de la actual propuesta.

Los proyectos y equipos presentados en este trabajo pretenden ofrecer una alternativa de bajo costo para los pequeños y medianos empresarios, que les permita deshidratar sus productos sin la necesidad de invertir en una planta deshidratadora. En el mercado del deshidratado tienen prioridad los grandes productores, quienes consiguen mejores precios y disponibilidad para su producción.

\section{El deshidratado solar}

El procedimiento para llevar a cabo el secado o deshidratado debe seguir una determinada secuencia. Primeramente la fruta u hortaliza debe ser dispuesta en bandejas con fondo de malla de modo que no se toquen o superpongan. La fruta debe ser cargada en las bandejas tan pronto como se prepara, para evitar que las piezas se peguen entre sí. Se debe evitar la luz solar directa ya que blanquea el color y reduce el nivel de vitaminas A y C. La temperatura de secado debe ser controlada para evitar el sobrecalentamiento y el deterioro.

Si la temperatura de secado es muy alta, especialmente al inicio del secado, el exterior de la fruta u hortaliza se seca muy rápido y se endurecerá; esta capa dura y seca evitará la pérdida de humedad, por lo que el centro podría deteriorarse durante el almacenado. La mayoría de los frutos se secan a $60-70{ }^{\circ} \mathrm{C}$. Las frutas se secan hasta que tengan el contenido de humedad final deseado ( $15 \%$ convencionalmente). 
El secado artificial es un método controlado de secado. También es el más caro ya que requiere de una cámara de secado calentada por gas, electricidad o biomasa. Existen varios tipos y tamaños de secadores disponibles para satisfacer las necesidades de los productores. Las ventajas son que la velocidad de secado puede ser cuidadosamente controlada independientemente de las condiciones climáticas externas para lograr un producto seco de alta calidad. El costo de combustible para calentar el aire es el principal factor económico que afecta las operaciones de secado. Ver Tabla 1.

\section{Deshidratado solar indirecto}

En el secado indirecto no se exponen los alimentos directamente a la radiación solar, para disminuir la decoloración y el agrietamiento en la superficie de estos. Los secadores solares indirectos poseen una unidad colectora solar donde ingresa el aire y una cámara de secado separada donde se almacenan los productos a secar. En el secado solar indirecto el calor necesario para la evaporación se transfiere de forma convectiva desde el aire caliente hacia el material húmedo. Con el secado indirecto se alcanza un mayor control de las condiciones de secado, por lo que se obtiene un producto de mejor calidad. La Figura 1 muestra el principio de funcionamiento del secado indirecto. Sin embargo, son estructuras más elaboradas que requieren mayor inversión de capital en equipos y tienen mayores costos de mantenimiento que las unidades de secado solar directo.

\section{Ventajas}

1. Ofrece un mejor control sobre el secado, por lo que el producto obtenido es de mejor calidad que el obtenido mediante secado al sol.

2. La caramelización y daño por calor localizado no ocurren como los productos que están protegidos contra la radiación directa.
3. Se puede operar a mayor temperatura.

4. Muy recomendable para los cultivos fotosensibles.

5. Tienen una mayor eficiencia que el secado solar directo.

La selección del tipo de secador solar debe adaptarse al manejo del producto tanto húmedo como seco, acomodando el proceso de secado al producto con las características deseadas. El secador debe ser evaluado según sus costos y rendimientos. En la Tabla 2 se enumeran los puntos básicos a evaluar para seleccionar un secador solar.

\section{TECNOLOGÍAS INCORPORADAS POR EL CIE}

El Centro de Innovación Energética (CIE), de la Universidad Santa María, tiene como misión el desarrollo de tecnologías aplicadas que contribuyan al progreso social y económico sustentable. A partir del 2012 en el CIE se han desarrollado diferentes modelos de deshidratadores solares y colectores de aire, tanto en modelos dependientes como independientes de la red eléctrica, móviles y fijos.

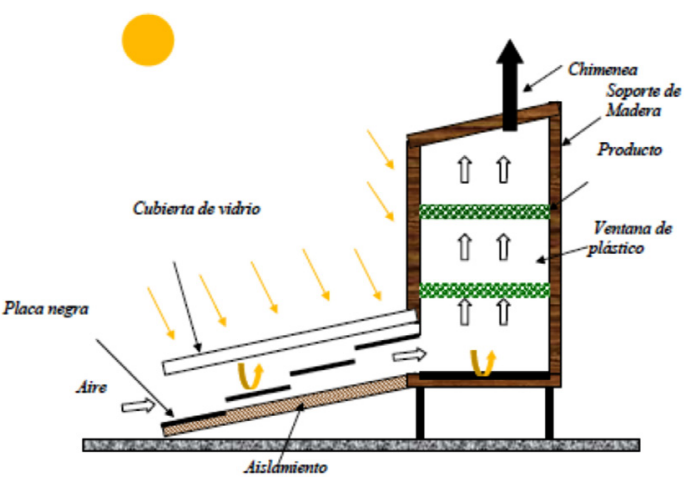

Figura.1 Componentes de un deshidratado solar indirecto.

Tabla 1. Características económicas de secadores convencionales con aire caliente.

\begin{tabular}{|l|c|c|c|}
\hline \multicolumn{1}{|c|}{ Tipo de secador } & Costo (US\$) & Capacidad (kg de prod. húm./24 h) & Inversión (US\$/kg seco) \\
\hline Solar de gabinete & 70 & 30 & 23 \\
\hline Gabinete a leña & 340 & 80 & 43 \\
\hline Gabinete pequeño & 85.000 & 500 & 1.700 \\
\hline Gabinete grande & 170.000 & 2.500 & 680 \\
\hline Túnel & 145.000 & 6.000 & 240 \\
\hline Cinta & 800.000 & 48.000 & 170 \\
\hline
\end{tabular}


Tabla 2. Parámetros de deshidratadores solares.

\begin{tabular}{|c|c|c|}
\hline 1 & Características físicas & $\begin{array}{l}\text { - Tipo y tamaño. } \\
\text { - Área del colector. } \\
\text { - Capac. de secado. } \\
\text { - Área y No bandejas. }\end{array}$ \\
\hline 2 & Comportamiento térmico & $\begin{array}{l}\text { - Radiación solar local. } \\
\text { - Tiempo de secado y veloc. de secado. } \\
\text { - Temp. y hum. aire de secado. } \\
\text { - Velocidad del aire. } \\
\end{array}$ \\
\hline 3 & Propiedades del producto & $\begin{array}{l}\text { - Caract. físicas húmedo y seco } \\
\text { - Acidez y corrosividad } \\
\text { - Tamaño de productos }\end{array}$ \\
\hline 4 & Características de secado del producto & $\begin{array}{l}\text { - Cont. inicial de hum. } \\
\text { - Cont. final hum. } \\
\text { - Temp. max. secado } \\
\text { - Tiempo de secado }\end{array}$ \\
\hline 5 & Económicos & $\begin{array}{l}\text { - Costo del secador. } \\
\text { - Costo de secado. } \\
\text { - Recup. inversión. }\end{array}$ \\
\hline
\end{tabular}

Las tecnologías de deshidratado solar desarrolladas están orientadas a soluciones económicas, como apoyo a pequeños y medianos productores, compatibles con el medio ambiente, buscando la eficiencia energética y utilizando materiales de fácil acceso.

Los modelos se desarrollan según las necesidades de los productores, según el volumen de producción, disponibilidad de conexión a la red eléctrica, la estacionalidad de las cosechas y las condiciones de secado de los productos. Las tecnologías consisten básicamente en sistemas de secado solar indirectos activos, es decir, son sistemas donde los alimentos no reciben la luz solar directa y funcionan mediante convección forzada. A nivel general, cuentan con un colector solar de aire, una cámara de secado y un ventilador.

Se distinguen dos líneas de productos, la primera, consiste en la modificación de estructuras existentes, que son del tipo fijo; y la segunda, consiste en equipos móviles de fácil transporte y montaje.

\section{Techo solar activo}

Es un desarrollo que nace de la necesidad de precalentar el aire para su utilización en procesos industriales o domésticos. El concepto se basa en la idea de aprovechar la radiación solar para incrementar la temperatura del aire circulante. El funcionamiento del techo solar activo opera con la radiación solar directa que incide sobre una superficie negra, la cual incrementa la energía interna de esta superficie y con esto su temperatura. Esta energía se transfiere mediante convección forzada a un flujo de aire que circula de forma constante sobre esta superficie colectora. Los techos activos se componen principalmente de dos partes: una superficie traslúcida y una placa absorbente de radiación color negro. Como placa traslúcida se utiliza policarbonato alveolar transparente y como placa o superficie absorbente de la radiación un panel aislante, el que se compone de una plancha trapezoidal de acero de color negro y un aislante de poliuretano. Este panel aislado se conoce comercialmente como Instapanel.

El calentamiento de aire, por medio de un techo solar activo, permite que la radiación solar penetre al sistema a través del policarbonato, el cual tiene una transmisividad de un $76-80 \%$. Esta radiación incide finalmente en la superficie metálica negra del panel aislante incrementado considerablemente su temperatura generándose un efecto invernadero que se ve incrementado por el color negro de la superficie metálica del panel. El conjunto policarbonato y panel aislado genera una cámara por la cual circula el aire e intercambia calor con la superficie negra que se encuentra a alta temperatura. Para implementar un techo solar activo (Figura 2) se requiere de un ventilador que permita la circulación del aire, forzando su ingreso y recorrido dentro de este, incrementando su temperatura. Se recomienda una velocidad del aire entre 2 y $4[\mathrm{~m} / \mathrm{s}]$. Este panel no presenta problemas frente a inclemencias climáticas 
ya que se utilizan materiales que están diseñados y garantizados para esta finalidad.

Los techos solares activos tienen una amplia versatilidad en su aplicación, ya que igualmente pueden ser utilizados como precalentadores de aire de uso industrial. Pueden ser utilizados igualmente para variados volúmenes de producción, ya que si con el techo solo no se logra alcanzar la meta de producción de secado, este se puede apoyar con la energía acumulada de agua caliente solar. A la fecha este sistema se ha implementado en cinco plantas procesadoras de nuez y de almendras. Esta tecnología se recomienda para medianos productores, debido a los requerimientos de inversión e infraestructura. Para volúmenes muy grandes de producción, este sistema puede representar un ahorro pero de menor magnitud (menor a 20\%).

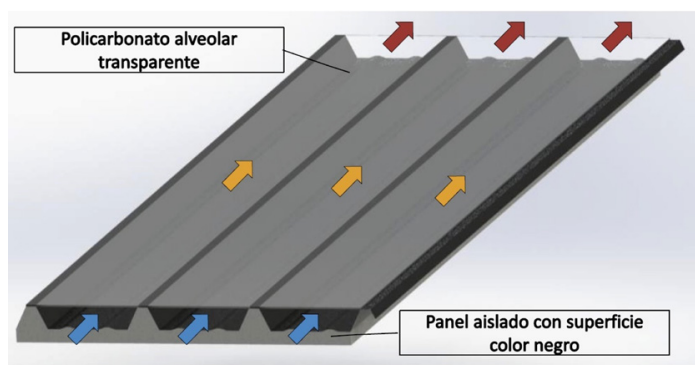

Figura 2. Diseño de un techo solar activo.

\section{Equipos móviles}

Los equipos diseñados por el CIE son de fácil traslado y fácil montaje. Esto otorga múltiples beneficios, por ejemplo no se necesita mano de obra para construcción en el lugar y pueden ser trasportados al sector de la cosecha para así producir ahorros en combustible de transporte de materia prima. Algunos equipos no necesitan conexión a la red eléctrica lo que los hace adecuados para funcionar en zonas rurales.

Existen dos diseños de equipos móviles, los que son del tipo contenedores y los secadores unifamiliares.

\section{Contenedores solares}

El diseño tipo container deshidratador solar (Figura 3) consiste en la incorporación de los componentes de techo activo solar en una sola unidad, como parte de la estructura principal, utilizando estos paneles como muros y techo de un container standard. Esto reduce los costos en materiales unificando todo los elementos que conforman el módulo deshidratador en una sola unidad de dimensiones similares a las de un container comercial, factor que facilita su movilidad para su funcionamiento en terreno

\section{Características:}

- Transportabilidad.

- Componentes comerciales.

- Menor número de piezas.

- Operatividad inmediata post-transporte.

Las características y capacidades generales son: (Figura 4).

El área de colector solar de 3 secciones de $10 \mathrm{~m}^{2}$. Capacidad máx. de 60 bandejas de 80 x $80 \mathrm{~cm}$.

Capacidad de carga productos: $1.000 \mathrm{~kg}$. Dim. cámara de secado: 2,2 x 2,2 x 5,3 [m]. Peso módulo deshidratador solar $950[\mathrm{~kg}]$. Potencia eléctrica del ventilador: 340 [W]. Conexión a la red de 220 [V].

El deshidratador, por su peso y dimensiones, es factible de ser transportado por cualquier camión (Figura 5). Es factible incluso de realizar procesos de deshidratado durante el viaje, conectado a un inversor $24 / 220 \mathrm{~V}$.

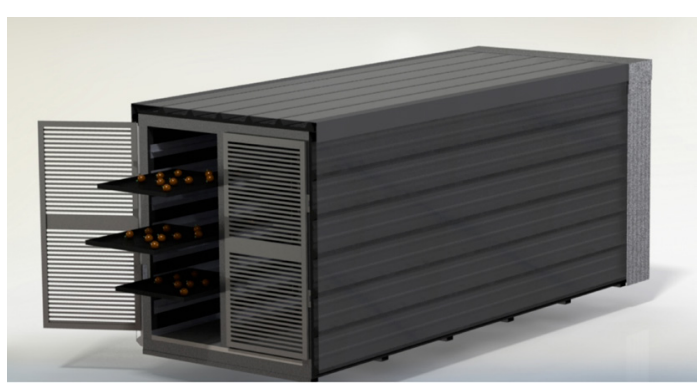

Figura 3. Contenedor deshidratador solar.

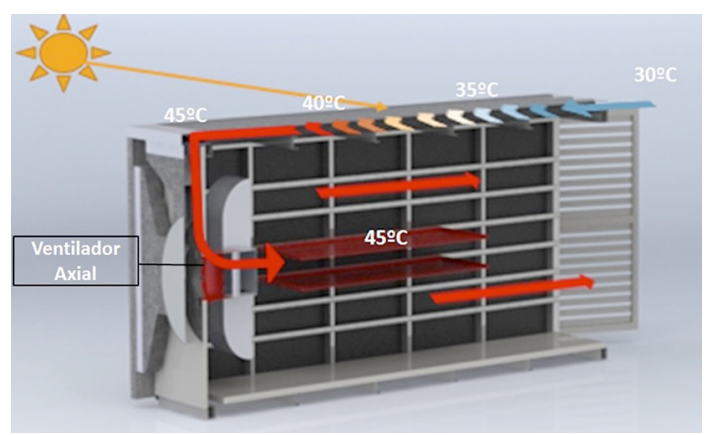

Figura 4. Principio de funcionamiento. 


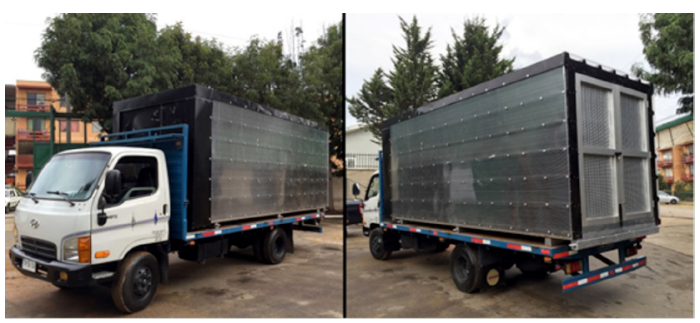

Figura 5. Contenedor solar móvil y operativo en viaje.

Las dimensiones mínimas que debe poseer la plataforma del camión son: ancho 2 [m], largo 5 [m].

El módulo deshidratador dispone de medición de humedad y temperatura y control manual del aire admitido por cada pared. Puede utilizarse con diversos productos que soporten distintas temperaturas máximas ya que el control de la temperatura dentro de la cámara de deshidratado resulta fundamental para conservar la calidad de las frutas y hortalizas.

Se consideran tres sistemas de control: termómetro con alarma, selector cilíndrico de activación de paneles o techos activos y variación del caudal.

\section{Deshidratadores unifamiliares}

Si bien el container deshidratador solar satisface las necesidades de Pymes agrícolas con una capacidad de 1.000 [kg], hay segmentos más pequeños de producción familiar o del pequeño emprendedor, que requieren deshidratadores de menor capacidad. Con este objetivo se desarrolló un deshidratador unifamiliar de 30 [kg], de menor costo y con funcionamiento apoyado por módulo fotovoltaico.

Las características y capacidades generales son:

Area del colector solar de $3 \mathrm{~m}^{2}$.

Capac. máxima $30[\mathrm{~kg}], 4$ bandejas de 80x80 cm. Dimensiones: ancho 1,0; alto 1,6; largo 3,2 m.

Peso 200 [kg]; ventilador 90 [W].

Kit fotovoltaico de apoyo

El deshidratador solar unifamiliar es un equipo diseñado para deshidratar diversos productos de origen vegetal o animal con ayuda de la energía solar en forma indirecta, evitando la radiación directa del sol sobre los productos. Ver Figura 6.

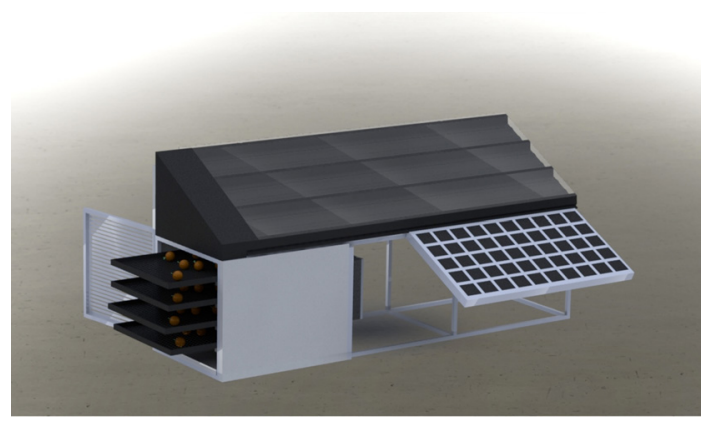

Figura 6. Deshidratador solar unifamiliar.

Se denomina unifamiliar por la capacidad de la cámara de secado de $1 \mathrm{~m}^{3}$, lo que equivale a unos $30 \mathrm{~kg}$ de carga de producto.

El tiempo requerido para lograr el deshidratado, con la humedad final esperada depende mucho de la superficie del producto expuesta al proceso de secado. Será más rápido deshidratar tomate, berenjena, zapallo italiano cortado en rebanadas, que durazno o uva, que son productos con mucha agua y poca superficie de evaporación. En los primeros, el deshidratado se alcanza en uno o dos días, en tanto con los últimos productos el proceso toma unos 10 días.

Para lograr el deshidratado solar en forma indirecta el aire ambiente se calienta en la cámara superior del equipo, que es doble. La parte inferior consta de una plancha de zinc con aislante, sobre la que se instala una plancha de policarbonato alveolar transparente. Se logra con ello una doble pared por donde se hace circular el aire succionado por un ventilador instalado en la parte trasera del equipo. El aire al circular por esta superficie se va calentando y es enviado por el ventilador a las bandejas del producto a secar.

Para operar en localidades sin energía eléctrica, se le incorpora un módulo fotovoltaico que permite que con la energía solar del lugar pueda energizar el ventilador durante las horas de operación. Como el ventilador trabaja con 220 Volt, se instala un inversor que transforma el voltaje de 24 en 220 Volt.

En conjunto con el interruptor del ventilador, se incorpora un Dimmer que permite variar las revoluciones del ventilador. Con menor caudal el aire se calentará más al ingresar, pero su cantidad será menor. Con mayor caudal habrá menor temperatura 
de ingreso pero el caudal de aire será mayor. Por ejemplo con nueces no se deben superar los $38^{\circ} \mathrm{C}$, así que requiere más aire que temperatura. Con uvas se puede trabajar con $55^{\circ} \mathrm{C}$, así que se podrían bajar las revoluciones del ventilador.

\section{RESULTADOS EXPERIMENTALES}

Entre los meses de enero y abril se llevaron a cabo pruebas en terreno con uvas, duraznos y nueces La Figura 7 muestra el resultado de la variación de temperatura en el interior del contenedor solar.

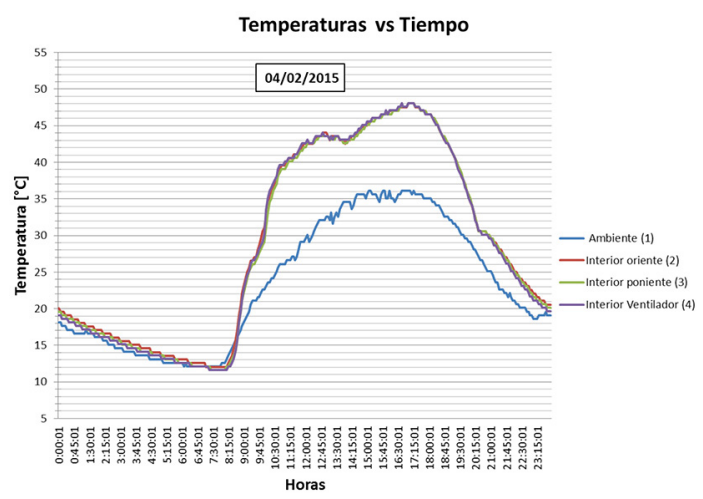

Figura 7. Variación de la temperatura interior.

En la Figura 8 se grafica la reducción en la humedad del aire ambiente al ingresar a las cámara de secado.

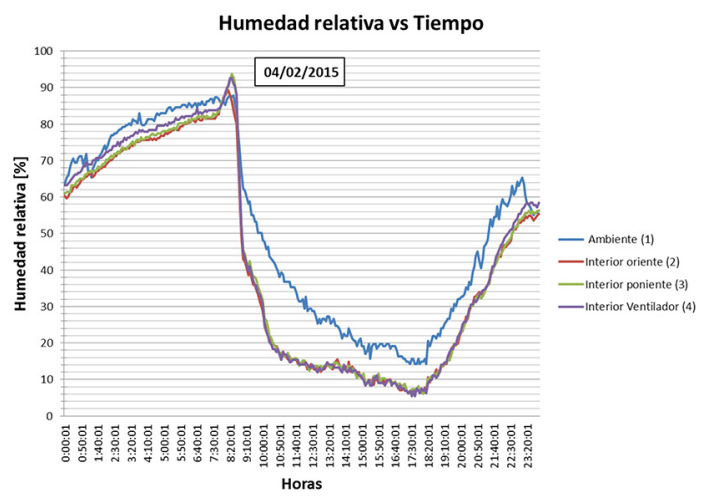

Figura 8. Variación en la humedad interior.

Al momento de conectar el ventilador, que coincide con el inicio de la radiación solar, se incrementa la temperatura ambiente, alcanzando un valor constante $45^{\circ} \mathrm{C}$ entre las 15 y 17 PM.
$\mathrm{Al}$ operar el equipo se comprueba una baja evidente de la humedad en el interior comparada con las condiciones ambientales. Esta diferencia de humedad se incrementa hasta llegar a valores tan bajos como $8 \%$.

Al trabajar con uva del tipo Flame, el proceso dura 10 días. La curva de secado de este tipo de uva tiene una pendiente decreciente, siendo evidente la pérdida de masa durante los primeros días, la que con los días se hace cada vez menor (Figura 9). Considerando que la masa inicial de la uva fue 100 [kg] y la final $29,5[\mathrm{~kg}]$ se produce una pérdida de $70,6 \%$.

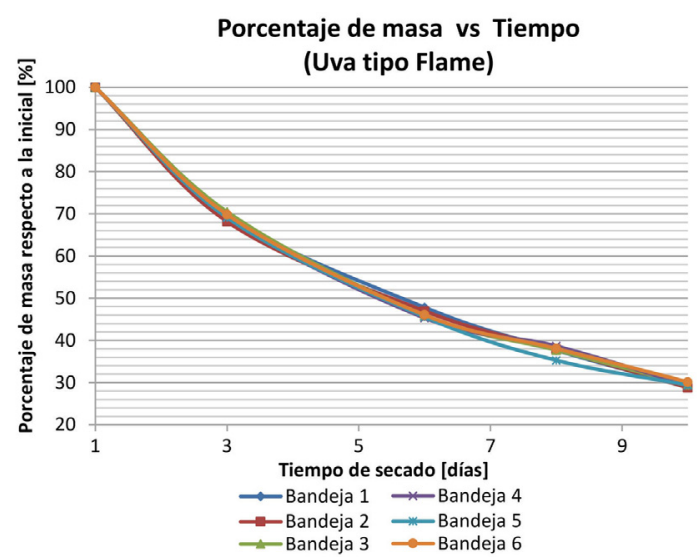

Figura 9. Curva de deshidratado de uva en container.

Se llevó a cabo otra experiencia con 11,25 [kg] de duraznos pelados en forma manual y dispuesto en dos bandejas de 80x80 [cm] Los duraznos no contienen ningún tipo de químico o colorante y se distribuyeron de forma homogénea en las bandejas de secado.

El proceso se extendió durante doce días, período en el que se logró extraer el 73,3\% de la masa inicial de los duraznos, obteniendo finalmente $3[\mathrm{~kg}]$ de huesillos. Ver Figura 10.

La calidad final de los huesillos fue excelente. La humedad final es la apropiada y su aspecto fue llamativo sin necesidad de utilizar colorantes. Ello se logró gracias a que no existe exposición directa a la radiación solar y en la cámara de secado hay muy poca luz, conservando un color atractivo y natural. Ver Figura 11.

Finalmente se ensayó el deshidratador con nueces, frutos que aportan una gran cantidad de fibra, hidratos 


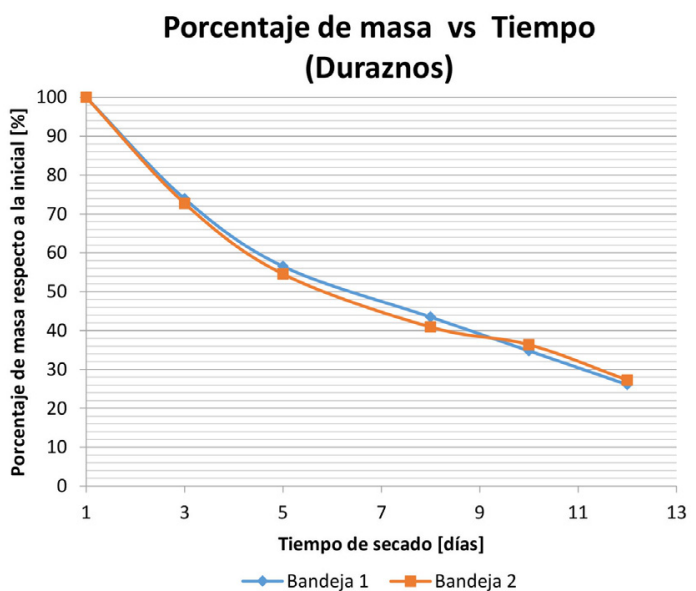

Figura 10. Curva deshidratado duraznos.

de carbono y proteínas, así como también vitaminas (A, B1, B6 y E). Previa a su comercialización se le debe reducir su humedad. En este caso el módulo deshidratador solar reduce los tiempos de secado, bajo condiciones ambientales óptimas desde cuatro días a un solo día.

\section{Costo de deshidratadores}

Los costos involucrados en la fabricación de los módulos deshidratador se agrupan en 12 ítemes, generándose una distribución porcentual de los principales factores en la fabricación, siendo los más relevantes con $18 \%$ de los gastos la mano de obra y perfiles de acero; en segundo lugar con $17 \%$ se ubican los módulos de techo y luego con $12 \%$ las bandejas interiores. Ver Figura 12.

Los prototipos de deshidratadores con aire caliente solar tienen los siguientes perfiles de costos asociados:

Container deshidratador $1.000 \mathrm{~kg}$ : US\$ 8.500,

Deshidratador unifamiliar $30 \mathrm{~kg}$ : US\$2.500,

Costo techo solar activo: $60 \mathrm{US} \$ / \mathrm{m}^{2}$.

\section{Participación de los ítem que componen} el deshidratador

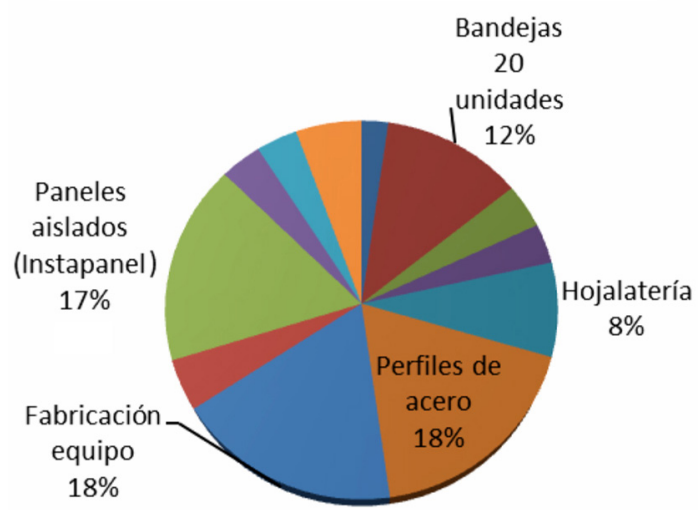

Figura 12. Distribución costo materiales contenedor.

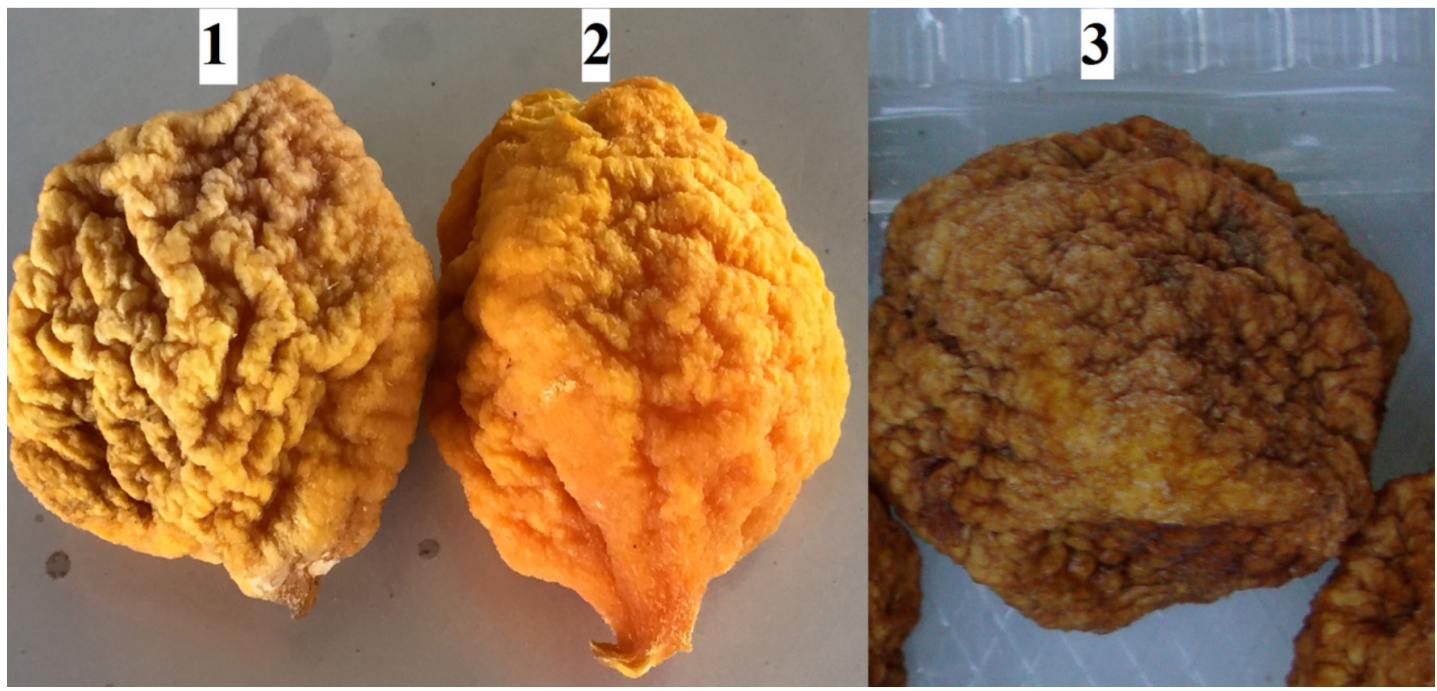

Figura 11. Comparación deshidratado durazno: 1 directo al sol con sulfitado; 2 en deshidratador con sulfitado; 3 Sin sulfitado en deshidratador. 


\section{CONCLUSIONES}

Los módulos deshidratadores solares han demostrado ser una alternativa muy apropiada a las necesidades requeridas por las Pymes agrícolas, con un diseño: unimodular, transportable, versátil, y sustentable con el medio ambiente, factores que lo hacen una alternativa muy atractiva al momento de agregar valor a la producción agrícola. La versatilidad de productos que se pueden deshidratar sumado a la posibilidad de usar un sistema fotovoltaico, lo hace sumamente interesante como componente para potenciar el empleo local en comunidades rurales aisladas o de difícil acceso.

Las pruebas empíricas en dos de los tres productos que generan más ingresos al país por sus exportaciones (nueces, pasas), han sido muy promisorias. Con la uva se obtuvo una textura y un color muy superior a los métodos convencionales, sumado a una reducción de tiempo en los procesos. Con nueces, se logran disminuir los tiempos de secado, de cuatro días al ambiente a solo 1,5 días en el módulo deshidratador, equivalente a un ahorro del $62 \%$ en tiempo. Con durazno, si bien los tiempos de secado fueron similares a los tradicionales, la apariencia lograda marcó una diferencia fundamental al obtener un producto sano, inocuo, atractivo y sin sulfitado.

\section{REFERENCIAS}

[1] Chilealimentos. "Alimentos Elaborados Posicionamiento de Chile en Mercados Mundiales". Santiago, Chile. Fecha de consulta: 6 mayo 2015. URL: http://www. chilealimentos.com

[2] Prochile. "Oportunidades en el Mercado Internacional para la Fruta Deshidratada". Santiago, Chile. Fecha de consulta: 11 mayo 2015. URL: http://www.prochile. gob.cl

[3] P. Fellows. "Food Processing Technology". Principles and Practice. 2a. Ed. Inglaterra, Woodhead Publishing Limited. 2000.

[4] G.L. Visavale. "Principles, Classification and Selection of Solar Dryers". In Solar drying: Fundamentals, Applications and Innovations. Singapore. 2012.

[5] S. Mustayen, S. Mekhilef and R. Saidur. "Performance study of different solar dryers: A review Renewable and Sustainable Energy Reviews". Vol. 34. June, 2014.

[6] A. Sreekumar, P.E. Manikantan and K.P. Vijayakumar. "Performance of indirect solar cabinet dryer". Energy Conversion and Management. Vol. 49, Issue 6. June 2008. 